\title{
On the concept of town-planning design of the agricultural cluster in a big city
}

\author{
Elena Akhmedova ${ }^{1}$, and Anna Zhogoleva ${ }^{*}, 1$ \\ ${ }^{1}$ Samara State Technical University, Institute of Architecture and Civil Engineering, 194, \\ Molodogvardeyskaya St, 443001, Samara, Russia
}

\begin{abstract}
The article deals with topical issues of town-planning design of the agricultural cluster in a big city as an integral part of the designing methodology for sustainable development of urban areas. The research subject is connected with ecological principles of town-planning, historical features of urban area development, agricultural settlement and specialization of the agricultural sector. The purpose of the study is to develop the town-planning concept of the agricultural cluster in a big city, the functional structure of its elements and to define principles of their organization within the context of methodology of area sustainable development. As a result of the research a number of principles for forming architectural and town-planning structures of the agricultural cluster have been formulated, including: the principle of sectorial townplanning, the principle of urban and rural areas integration, the principle of ecologization of cluster strategies and architectural and town-planning solutions, the principle of integrating landscape, agro-landscape and housing development, the principle of bio-positive design of buildings and complexes.
\end{abstract}

\section{Introduction}

Environmental security of sustainable development of the urban agglomeration can be carried out on the basis of a basin or landscape approach to the settlement system.

The analysis of historical development of settlement and land use in the Samara region [1] and international experience of the dynamics of large urban agglomerations development [2] shows that nowadays the Samara-Togliatti agglomeration is transiting from the stage of industrial agglomeration to agglomeration of the transformation period. It is the stage of transition to suburban land use, to more distributed forms of production, to formation of the services sector, transport and information infrastructure, to increasing demand for all types of infrastructure - airports, roads, telecommunications, areas with developed engineering systems, to creation of conditions for forming the economy of postindustrial type.

According to I.N.Yakovlev, the civilizational stage of the Samara-Togliatti agglomeration development can be defined as the stage of transition to the developed industrial agglomeration, in which the priority of the settlement is sustainable development

\footnotetext{
*Corresponding author: annazhogoleva@yandex.ru
} 
of the town-planning paradigm - the security of the living environment, the environmental planning principle, the prevailing concept of the developed area as interrelated (agglomerative), dominative support of the town-planning process which is a regulating and governing one, as well as keeping the balance of interests of all participants of the townplanning process [3].

International examples show that development of regional agricultural clusters is townforming for spatial agglomerative subsystems [4]. If problems of agriculture development are solved with the help of the agricultural cluster, these solutions will contribute to interdevelopment or urban and suburban areas, both in socio-economic aspect, and in townplanning, as under the conditions of clustering activity, they will be connected by a single socio-spatial process. Such objects as agro-parks, breeding nurseries, city farms, mansions, urban and suburban greenhouses, public landscaped areas, gardens with perennial crops, garden and holiday villages, the areas carrying various crops can be organized in a single "green" town-planning structure, that will provide sustainable development and agglomerations. The development of agriculture and relevant industries is important to ensure "food security" of agglomeration using local resources, to keep the ecological balance of agglomeration, development of rural-urban lifestyles.

\section{Materials and Methods}

\subsection{Regional study}

The designed agricultural cluster of the Samara region covers urban and rural areas. Its development is to be in the direction of the Kinelsky district. Further development will be carried out in the direction of Otradnensky and Pokhvistnevsky districts.

Landscape conditions of agricultural cluster development are based on the basin principle of settlement. The landscape frame of the agricultural cluster is formed by the river floodplains of Samara and Bolshoy Kinel and surrounding areas favorable for accommodation of residential development and certain types of agro-industry required for the cluster. The landscape frame is an internal cluster frame, that defines its structure, location of objects and their further development. The location of the objects in the cluster is determined by both the integration of landscape systems into the structure of the cluster and by concentration of certain resources in certain areas of the landscape [5].

In the direction of Kinel and Otradnensky districts of the region there are areas which are natural zones of forest-steppe and steppe. The soil is ordinary black humus earth. Besides rivers there are other water resources - reservoirs. A significant part of smooth slopes is plowed; areas located along the rivers are used as hayfields and pastures. On the banks of the rivers it is possible to organize new recreational facilities of agro-tourism, as well as fish farms, the production technology of which can be combined with crop farming as far as energy saving technologies are concerned.

The agriculture industry specialization in meat-and-dairy cattle farming and vegetable growing is conditioned by the suburban character of the area [6]. Plots in this area have medium and high factor indicators affecting the agriculture management as there exist conditions for its development both natural and economic.

"Growth points" and "outbound" tendencies of agglomeration development. In the direction of Kinel and Otradnensky districts of the region there are inter-settlement centers on the basis of "growth poles": Kinel-Cherkassy village and Pokhvistnevo urban district are the "growth poles" of the first priority in outer-agglomeration areas of the region. The proposed "growth points" of the agglomeration are located on the "outbound" directions of agglomeration development. 
In the direction of Kinelsky district important railway hubs are located. The district's importance has been formed throughout the history of the transport network development in the region. Now in the direction of this axis there are settlement centers, one of which is the town of Kinel. Kinel is considered to be one of the most important Eurasian railway hubs. Here is the crossing of the TRANS-Siberian railway and the railway track from the SouthEast of Orenburg - Kazakhstan - Central Asia [7].

\subsection{Methods of sustainable architectural and town-planning organization of the agricultural cluster}

Sustainable organization of the agricultural cluster is based on a balanced architectural and town-planning organization of cluster structures, which should be based on a number of methods of forming sustainable architectural and town-planning structure of the agricultural cluster. Among them are:

1. The method of sectorial town-planning. The formation of the cluster town-planning structure is based on sectorial planning of agglomeration areas - the development of suburban plots that form a part of the sector at one of the outbound directions of the city development. Location of plots (urban, suburban, rural) forms a cluster sector, covering agglomeration areas.

2. The method of urban and rural areas integration. Urban and rural areas are combined in a linearly-compact distributed agglomerative mono-structure of rural-urban lifestyles. The basis for the development of the cluster is the integration of the countryside and the city by establishing the inextricable links of information transmission, products delivery and also by adaptation of agriculture to the city through the creation of CPUL objects and integration of urban lifestyle into the countryside [8].

3. The method of areas and plots differentiation. Hub segments of the cluster (city) include trade-logistic and administrative business functions, compact cluster elements (campus) research function, distributed structure (rural settlements) - agricultural production. Distribution of functions depends on the availability of area resources, town-planning and natural conditions.

4. The method of junction planning solutions of the cluster complexes. The cluster in regard to town planning is a continuous structure, some parts of which perform a junction function. They can accommodate logistical, social and business complexes. The complexes located on these sites, are designed as junction urban elements, the characteristics of which are determined not only by their functional cluster program, but by their location (transport interchange, logistic, multi-functional, high-density, highly urban solutions) [9]. Such junctions in the AGC project of the Samara region are Ust-Kinel agro-park, a business center in the city of Samara, a transport hub in the town of Kinel.

5. The method of the landscape, agro-landscape and housing development integration. The project involves the development of a continuous productive urban landscape (CPUL) in Samara and its suburbs. The CPUL is represented by public gardens, greenhouses, vegetable gardens, glasshouses, farms located in the areas accessible for all residents, such as public parks, squares, new objects (the city farm, eco-villages). Dacha communities in the suburbs could also become a part of the CPUL as well as private plots with detached houses in the city and suburbs.

6. The methods of bio-positive design of buildings and complexes. The concept of the cluster formation refers to the principles of sustainable area development reflected in the organization of the cluster structure, in the location of the cluster objects, their operation and production processes. The design of the cluster objects involved the use of water efficiency technologies, energy saving, special technologies of heating and ventilation, recycling of resources. These technologies are applied to the cluster objects, including the 
installation of vertical farms and wetlands in the structure of architectural objects. The agricultural sector can also use eco-friendly technologies - plants cultivation according to the principles of the hydroponic technology and organic farming, the installation of wind turbines, providing energy for buildings and industrial sites, the use of secondary energy at agricultural production companies when they are diversified (livestock farms are completed by greenhouses, biogas plants are installed) [10].

\section{Results}

In accordance with the selected methodology, Master's Degree Student Maltseva Elena, under the supervision of Professor E.A. Akhmedova and Associate Professor A.V. Zhogoleva, in 2014 in the framework of the Master's thesis developed a pilot project of the cluster complex in Samara, presented in Figures 1 and 2.
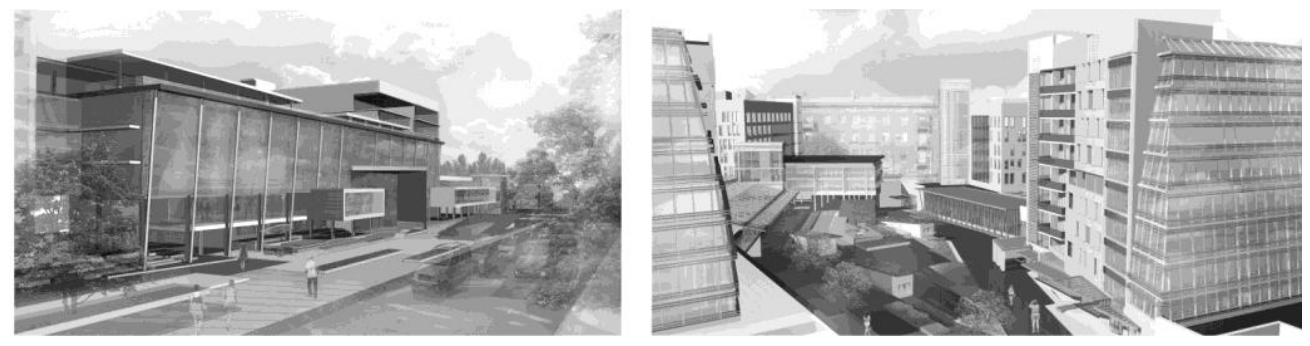

Fig.1. A pilot project of the cluster complex.

The city cluster complex accommodates:

1. An experimental eco-village with low-rise individual housing.

2. A business center.

3. A research center.

4. A city farm.

5. A trading-logistical center.

1. The experimental eco-village with low-rise individual housing is located between Kalinina and Vyazemskaya streets. The eco-village has become a part of the cluster, it has been constructed according to sustainable development technology, it is involved in the production chain and product delivery.

The concept of the cluster formation is inseparable from the methods of area sustainable development. It is reflected in the planning solutions of the cluster complexes, such as development of the agro-park space using the energy efficient technology, water efficiency technology, special technology of heating and ventilation, recycling of resources, as well as environmental rehabilitation by creating a business center on the abandoned site [11]. During the reconstruction of the village the relationship between the social, economic, environmental processes was taken into account. The main environmental issues are connected with rational use of natural resources and reduction of adverse environmental impact. Based on the methods of sustainable development the following reconstruction measures were proposed:

- engineering. The existing buildings are to be equipped with engineering systems, based on technologies of energy saving, recycling of resources. The use of in-house energy-saving technologies is specified in the project, as well as the possibility to use devices that provide natural light and ventilation, integration with the city's power system. The project also specifies the installation of the effective system of water supply and sewage that ensures maximum water purification before discharging it into reservoirs, this system is connected 
to local systems of «grey» water purification, recycling of used water, drainage network. For creation of engineering infrastructure the project takes into account the possibility of using renewable energy sources both local and district;

-landscape-planning. The area is landscaped in the following way: green design of private garden plots, landscaping for protective purposes mainly along streets and driveways, but the common area is not landscaped. So it is planned by the project of this site to landscape its common areas such as squares and alleys as part of a public center. When reconstructing and developing the transport framework, it is intended to garden avenues, to beautify and develop landscaping for protective purposes. Along Kalinina street the restoration and development of protective landscaping is planned, also the same measures are to be taken along Rynochnaya street that separates the settlement from the trade and logistics cluster objects located along the railway tracks. Along the driveways, Turkmenskaya and Rynochnaya streets, the protective landscaping and alleys are to be designed;

-social. For social activities of the village a public center (3-5 storeys) is to be constructed. The center combines management, communication, leisure functions. For the purpose of the area development according to the principles of sustainable development and as the part of the agricultural cluster the construction of an ecological center is planned. So on the territory of the center it is possible to place public built-in and -on greenhouses (technologies of their use will also affect the energy efficiency of the center and the secondary use of sources, the use of excess heat), and centers of training, socialization; to organize village meetings to solve management and development problems;

- transport. The existing transport infrastructure needs renovation and development to ensure safe passage through the village and to organize parking. Existing streets and driveways are to be reconstructed according to the project. At the village entrance it is planned to organize parking lots for temporary and permanent storage of automobiles belonging to village residents and visitors, as well as parking spaces near the public center; 

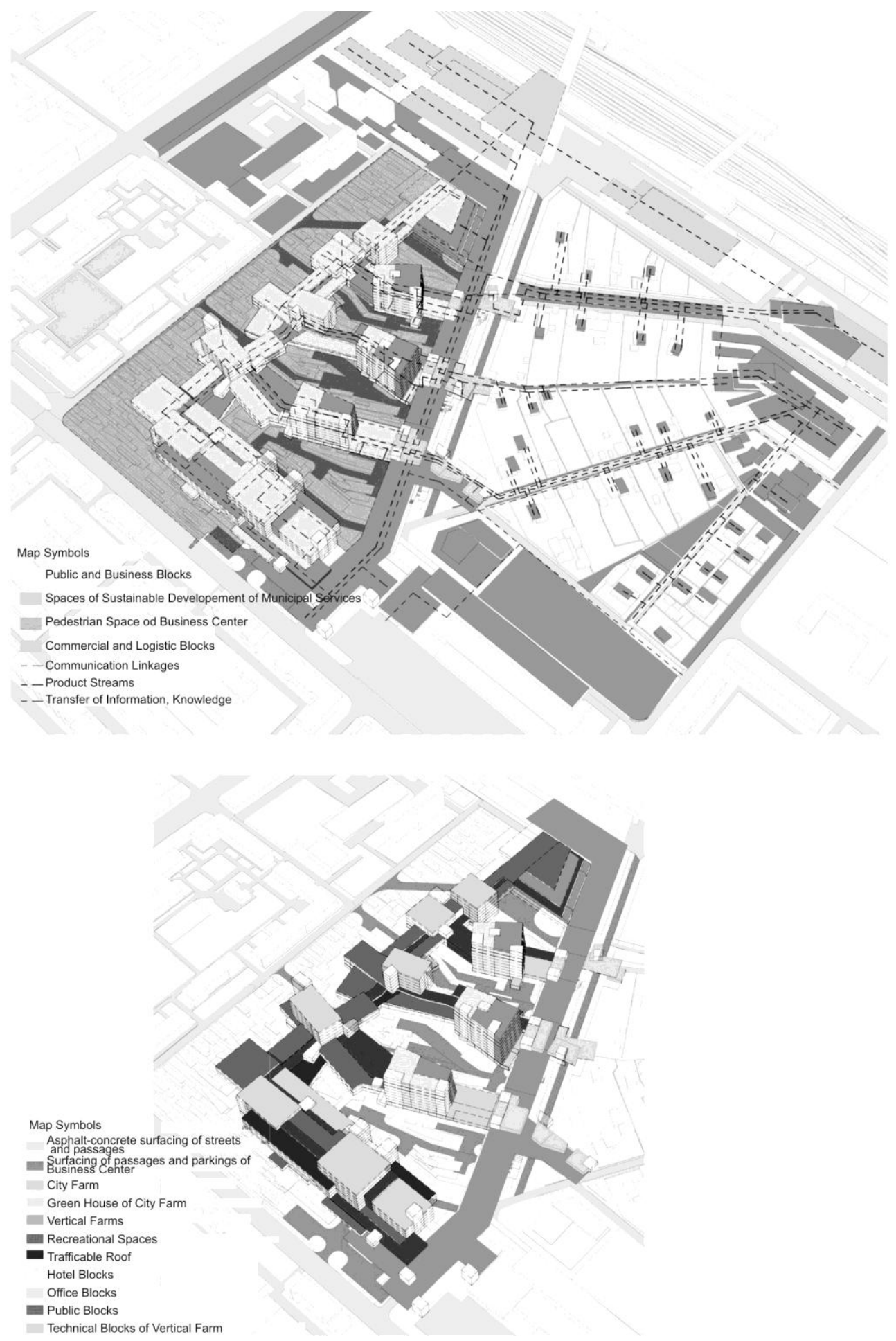

Fig.2. Solution schemes of the cluster complex. 
2. The business complex combines social and business functions. The center serves to transmit information to its visitors (a landscape design center, a garden center, an exhibition hall, an information center), and to offices of the companies participating in the work of the cluster and centers located in the public-business block. Public buildings are connected by passages with three hotel blocks. These blocks combine the functions of hotels and vertical farms. Vertical farms are used as demonstration and experimental sites for producing foodstuff delivered to all restaurants of the complex or shops.

Vertical farms are stations for growing different crops. Under each block of vertical farms on the first and second underground floors there are engineering premises for accommodating equipment of energy efficient technologies and technologies for secondary use of resources, including premises, serving the system of wetlands. In vertical farms the plants are grown according to hydroponics and aeroponics technologies.

Specialized devices by company VertiCrop ${ }^{\mathrm{TM}}$ are used. They need a lot of room, thus double-height spaces are designed in the complexes. Monitoring and maintenance of vertical farms is carried out from specialized premises located on each floor. The lower storeys of separate functional blocks accommodate administrative and technical sections of vertical farms (storage of goods, packaging material, containers, sorting of goods). These premises are connected with sheltered greenhouses, located on the city farm, linking these systems by the integral planning and functional solution. The combined function of the hotel and vertical farm gives guests of the cluster an opportunity to review agro - and ecotechnologies in the complex.

3. The research center is integrated in the structure of the new housing development and provides research, informative or demonstration functions for visitors, residents from nearby houses, representatives of the industry investors, firms located in the business center. The research center is connected with the business center by a passage from the side of social and business blocks and the city farm. The center is busy with the scientific forecasting and technology of the cluster production based on promising trends and technological solutions related to agricultural sectors of production. Also, the center deals with professional development of managers and specialists of agricultural enterprises. The network of informative centers will transfer these functions to the region.

4. The city farm is a part of the agricultural and social subsystem of the cluster and of CPUL. The city farm is located between the downtown and the village. It is a two-level gallery bridge with areas of open productive landscape, greenhouses, a fair and exhibition pavilions. It forms a space for transmitting information and delivering products. It is the intersection of industrial, social, informational substructures.

\section{Discussion}

The content of the pilot project is expanding because of the use of methods of suintroduced in this study. Architectural objects, landscape objects, grounds and project sites are integrated into biopositive environment. The results of the study made it possible to complete an important section of the pilot project "Innovations and landscape", which introduces some new ways of using sustainable architectural and landscape solutions.

The following measures for beautification and landscaping of the cluster are suggested there:

- pedestrian sidewalks are paved with decorative durable water resistant covering - ecopavement. Waste storm water from city courtyards, gardens, parks, walkways and squares can leak into the ground, renewing ground waters. The polymer binder for eco-pavement contributes to this process, it consists of $50 \%$ of natural oils and has the property to absorb pollutants from the water penetrating the road covering. 
- inside there are recreational areas for both visitors of the complex and its staff [12]. These areas are formed by terraces at different levels, lawns with various shrubs, recreational zones;

- the project involves the use of the following landscaping elements: flower beds, lawns, shrubs, tall-trunked landscaping, productive landscape, agro-landscape. In order to save potable water for irrigation water-efficient landscape is used. For this purpose the site is landscaped with plants that require minimal watering, and they are adapted to the local climate. The "grey" and purified rain water is used for their irrigation. The landscaping of this area is also carried out according to the technology of intensive gardening - the "roof garden" (multi-layered structure, enabling the planting of tall-trunked trees, shrubs and lawn-plants, as well as development of the exploited areas);

- to landscape inaccessible roof parts of some buildings it is designed to use the technology of extensive landscaping with rolled lawns, that improves the aesthetic appearance of the building and protects the roof structure, providing additional insulation and absorption of dust and noise;

- as a biological method of purification of grey water for its secondary use for commercial purposes and for plants watering, the technology of water pass through the system of wetlands (botanical ponds or cassettes), which are located in the premises of the business center for year-round operation is applied;

- in the interior design of the complex (recreation areas, public spaces) the technology of vertical gardening is used. A modular system by «Woollypocket» company is applied. It is a grid of "pockets" made from 100\% recycled plastic bottles. These systems are attached to the wall made of any material with special screws. An automatic watering system at the special back panel is used. Behind the "pockets" there are pipes of small cross-section that are connected to a common water-supply system or pipes, where rainwater circulates.

\section{Conclusions}

The analysis of the historical development, settlement and reclaiming of the territory of the Samara region has shown that the specific character of the regional agricultural industry was historically predetermined by its geographical position and the existing agricultural settlement. Regional study has identified trends and directions of the agricultural cluster development in the structure of the polycentric agglomeration on the territory of the Samara region, and highlighted focal points and outbound directions for developing the cluster structures. Within the theoretical study a number of principles to form urban and townplanning structures of the AGC has been formulated, including: the principle of sectorial town planning, the principle of urban and rural areas integration, the principle of junction planning solutions of the cluster complexes, the principle of integrating the landscape, agro landscape and housing development, the principles of bio positive buildings and complexes design. The experimental design of the cluster complex was based on the methodology of sustainable design.

\section{References}

1. A.K. Sinelnik, Town-planning history of the Samara region (2000).

2. V.Ya. Lubovniy, Cities of Russia: alternatives of development and management (2013).

3. I.N. Yakovlev, Structure formation of settlement frame in the Samara region (historical analysis, planning assessment and development forecast) (2008).

4. URL: http://www.ontariofoodcluster. com/success-profiles. 
5. A.S. Huhrin, Economics, labor, management in agriculture 6, 20 (2011).

6. Strategy of socio-economic development of the Samara region until 2025. 5.2.1. Agroindustrial cluster.

7. E.A. Akhmedova, Town-planning regulation of regional environment (1993).

8. S.F. Patinkin, T.P. Bykova, Development of clusters: subject matter, current approaches, international experience (2008).

9. V. Tarasenko, Territorial clusters: seven management tools (2015).

10. D.I. Fayzrakhmanov, Bulletin of the Kazan GAU (Economic sciences) 3 (25), 56-58 (2012).

11. A.S. Huhrin, Economics of agricultural and recycling enterprises 7, 31 (2008).

13. V.M. Melnikova, N.A. Mastalerz, Urban Construction and Architecture 1, 31-37 (2011). 